\title{
Research on Risk Perception of Fashion Online Shopping by Chinese Female College Students' in Guangdong
}

\author{
Hewei $\operatorname{Tian}^{1}$ and Youngsook Lee ${ }^{2}$ \\ Dept. Fashion Design, Tongmyong University, Korea \\ 2young@tu.ac.kr
}

\begin{abstract}
In this paper, signal detection theory (SDT) is proposed in order to quantitatively analyze the perceived risk of Chinese female college students' fashion online shopping, Firstly, it defines the concept of female college students' perceived risk, analyzes the main types and manifestations of online shopping perceived risk. Based on the literature review, combination with the risks of female college students' online shopping, a questionnaire was developed. 20 female college students from Lingnan Normal University were randomly selected as test subjects. SDT is used to evaluate the sensitivity and reaction tendency. The sensitivity value and reaction tendency value of the risk response were obtained. The results of the study show that the sensitivity value is [-4.65, 0.93], which is generally low and the difference was small, but the maximum reaction tendency value is 12.2650 , and the minimum is 0.7191 . The values of this indicator vary widely, and this is basically inconsistent with the actual situation, indicating that the SDT proposed in this study can be used to evaluate the perceived risk of female college students' fashion online shopping scientifically and accurately.
\end{abstract}

Keywords: Female college student, Online shopping mall, Perceived risk ability, SDT evaluation

\section{Introduction}

With the popularity of the Internet, online shopping has become an important form of shopping, which is constantly changing people's consumption awareness and lifestyle. According to the report by the China Internet Network Information Center, as of December 2018, the number of online shopping in China reached 610 million. The scale of China online shopping has surpassed the United States, making China the world's largest online consumer market.The existing researches mainly focuse on the perceived risk concept and influence factors. There are relatively few researches on the perceived risk ability of online fashion purchase behavior, especially how to quantitatively evaluate the female college students' online fashion purchase perceived risk ability. Based on the research of the existing online shopping risk types, we combine the specific risk scenarios of female college students' online shopping process, sets up the questionnaire, and use the SDT to evaluate the online shopping perceived risk ability of Chinese female college students, which will provide reference for the cultivation and promotion of female college students' online fashion purchase perceived risk ability.

\section{Theoretical background}

Article history:

Received (January 6, 2019), Review Result (June 9, 2019), Accepted (September 12, 2019) 


\subsection{Status of China's online shopping mall}

Although the rapid development and huge market scale of online shopping malls is obvious in China, there still exists loopholes such as logistics distribution (Kyoung Suk Choi Chae Hun Song, 2013), personal information outflow and payment risk (Oi Sul Jeon Sung Kyu Park,2009) in spite of bringing convenience to consumers. In the first half of 2018, the China network security center (CNNIC) received a total of 54,190 accident reports, which is the increase of 12.2 percentage points compared to 48,283 in the same period of 2017. In addition, in the first half of 2018, National Internet-connected Report Department received 390.82 million reports in total (117.1\% increase from compared to 17.978 million of the same period of 2017. It reveals that China's network mall shopping security situation is not optimistic.

\subsection{Perceived risk}

The initial concept of Perceived Risk was extended from psychology by Bauer [1]. He believed that the expected results of purchasing behavior that could get consumers down may not be predicted. Therefore, consumers' purchase decision implies uncertainty about the result, which is the initial concept of risk. Jacoby\&Kaplan divided perceived risk into six types, including money risk, performance risk, physical risk, social risk, psychological risk and time risk that may be associated with product procurement. Simpson\&Lakner believed that among the purchasing environments of online shopping, consumers' perceived risks can be divided into economic risks, social risks, outcome risks, personal risks, consumer privacy risks and so on, just like traditional transactions.

\subsection{Signal detection theory (SDT)}

Signal detection theory (SDT) is a basic theory of probability, which can be used to quantitatively diagnose the performance of systems. SDT is first developed in electrical engineering based on the statistical decision which is widely used in decision performance analysis. SDT has been widely applied in military command and control, weather forecasting, medical and personal decisions. In addition, relevant studies have attempted to use SDT to evaluate the conflict judgment performance of air traffic controllers and the accuracy of the conflict judgment system of the old air traffic control system[2]. R Parasuranman proposed an algorithm that can be used to calculate the values of four results, which can satisfy formula (1):

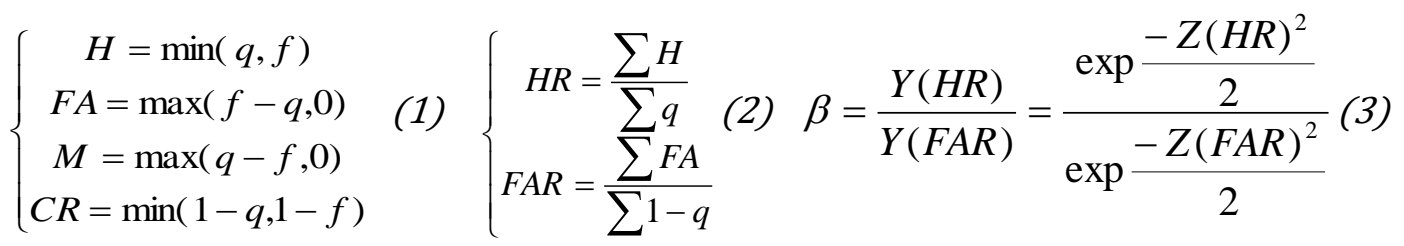

With the definition of HR and FAR as the female college students' perceived risk response sensitivity and reaction tendency respectively, HR and FAR can be calculated by formula (2)[3]. A simple example is given for formula (1) and (2). Two risk states are assumed. The (q,f) value of risk condition 1 is 0.75 and 0.65 , and the $(\mathrm{q}, \mathrm{f})$ value of risk condition 2 is 0.85 and 0.95 . Therefore, the $\mathrm{H}$ value of the two risk states should be 0.65 and 0.85 , and $\mathrm{HR}$ is the sum of all $\mathrm{H}$ values $(0.65+0.85)$ divided by the sum of all $\mathrm{q}$ values $(0.75+0.85)$, resulting in 0.9375 . Calculating FAR by the same method gives the FA distribution of the two risk conditions, that is, 0 and $0.1 . \mathrm{M}$ and $\mathrm{CM}$ are not used frequently because they provide no new information[4].In general, in SDT, the reaction sensitivity is represented by parameter $\alpha$ and the reaction 
tendency is represented by parameter $\beta$. The method to calculate reaction sensitivity is given in formula(3). In this study, the value of $\alpha$ represents the sensitivity of female college students to risk conditions [5]. $\mathrm{Z}(\mathrm{HR})$ represents the abscissa of the normal distribution HR, while $\mathrm{Z}(\mathrm{FAR})$ represents the abscissa of the normal distribution FAR.

$$
\alpha=Z(\mathrm{AR})-\mathrm{Z}(\mathrm{FAR})=\Phi^{-1}(H R)-\Phi^{-1}(F A R)
$$

The calculation formula of reaction tendency $\beta$ is shown in formula (4). In this study, $\beta$ represents the response tendency of female college students to the risk conditions, Y(HR) represents the ordinate of the normal distribution HR, and Y(FAR) represents the ordinate of the normal distribution FAR.

\section{Research methods and procedures}

There are 13 questions were collected as the basic data of the testees in questionnaire, and another 12 questions were used for the SDT evaluation, as shown in Table 1.The data in this study were collected using the questionnaire survey method. The research subjects were female college students from Lingnan Normal University in Guangdong Province, China. The survey was conducted in April, 2019. Before the implementation of the survey, four experts were invited to assess the risk level or level of the risk scenarios for the twelve questions in Table 5. The four experts include two network security supervisors (China Guangdong Cyber Security Center) and two academic experts (China-Taiwan Special Education Research Institute). According to SDT's first research, because this method is to determine the exact value of risk perception sensitivity and reaction tendency, it is quite sufficient to select 20 female college students for testing. Their answers are summarized and used for analysis and calculation.

Table 1 . The 12 questions to represent 12 causation scenarios

\begin{tabular}{|c|c|}
\hline No. & Risk scenario \\
\hline 1 & The quality of clothing purchased by the online mall is better than that of the webpage \\
\hline 2 & The size of the clothing sold in the online mall is very accurate. \\
\hline 3 & The color and design of the clothing sold in the online mall is very good[6]. \\
\hline 4 & Online malls are very risky to pay when trading. \\
\hline 5 & It is wasteful to buy clothing in the online mall. \\
\hline 7 & The clothing distribution purchased by the online mall is very punctual[7]. \\
\hline 8 & Personal information will be leaked after the online store purchases clothing. \\
\hline 9 & Online malls will be harassed by merchants after purchasing apparel products. \\
\hline 10 & Clothing purchased by the online store will be delivered to the wrong address. \\
\hline 11 & The behavior of buying clothes by online mall will be despised by friends around you[9] . \\
\hline
\end{tabular}




\section{Results and discussion}

The survey was conducted targeting 20 female college students from Lingnan Normal University in Guangdong Province. The survey period was from April 9 to 16, 2019. From the results of the investigation, female students in the second grade accounted for the highest proportion (35\%). In the profession, the artistic, physical and sports majors have the highest proportion of professionalism (35\%). The monthly disposable pocket money of 1500-2000 yuan accounted for the highest proportion (30\%), and the daily browsing time of the apparel products in the online mall, 1-2 hours (35\%) accounted for the highest proportion. According to the data in Table 2, and the formulas (1), (2), (3) and (4), the risk sensitivity and reaction tendency indicators of the first female college student can be calculated as shown below.

$$
\begin{aligned}
& H R=\sum H / \sum q=6.70 / 7.58=0.8839 \\
& F A R=\sum F A / \sum(1-q)=1.16 / 4.42=0.2624 \\
& \alpha=Z(\mathrm{AR})-\mathrm{Z}(\mathrm{FAR})=\Phi^{-1}(H R)-\Phi^{-1}(F A R)=-1.19-0.94=-2.13 \\
& \beta=Y(H R) / Y(F A R)=0.7662
\end{aligned}
$$

Table 2. Statistical results of the first student

\begin{tabular}{|c|c|c|c|c|c|c|c|c|c|c|c|c|c|}
\hline & $\mathrm{Q} 1$ & $\mathrm{Q} 2$ & $\mathrm{Q} 3$ & $\mathrm{Q} 4$ & $\mathrm{Q} 5$ & $\mathrm{Q} 6$ & $\mathrm{Q} 7$ & $\mathrm{Q} 8$ & $\mathrm{Q} 9$ & $\mathrm{Q} 10$ & $\mathrm{Q} 11$ & $\mathrm{Q} 12$ & Sum \\
\hline $\mathrm{q}$ & 0.72 & 0.68 & 0.85 & 0.43 & 0.94 & 0.37 & 0.42 & 0.91 & 0.79 & 0.10 & 0.83 & 0.54 & 7.58 \\
\hline $\mathrm{f}$ & 0.63 & 0.81 & 0.75 & 0.64 & 0.82 & 0.47 & 0.73 & 0.52 & 0.86 & 0.31 & 0.65 & 0.67 & - \\
\hline $\mathrm{H}$ & 0.63 & 0.68 & 0.75 & 0.43 & 0.82 & 0.37 & 0.42 & 0.52 & 0.79 & 0.10 & 0.65 & 0.54 & 6.70 \\
\hline $\mathrm{M}$ & 0.09 & 0 & 0.10 & 0 & 0.12 & 0 & 0 & 0.39 & 0 & 0 & 0.18 & 0 & - \\
\hline $\mathrm{FA}$ & 0 & 0.13 & 0 & 0.21 & 0 & 0.10 & 0.31 & 0 & 0.07 & 0.21 & 0 & 0.13 & 1.16 \\
\hline $\mathrm{CR}$ & 0.28 & 0.19 & 0.15 & 0.36 & 0.06 & 0.53 & 0.27 & 0.09 & 0.14 & 0.69 & 0.17 & 0.33 & - \\
\hline
\end{tabular}

In the SDT theory, the probability of $100 \%$ and the probability of 0 (false report) in the risk state are non-existent, so $\mathrm{HR}=0.99$ and $\mathrm{FAR}=0.01$ are assumed, By using formulas (2) and (3), the maximum value of sensitivity is calculated to be 4.65 . When $H R=0.01$ and $F A R=0.99$, the minimum value of sensitivity is calculated as -4.65 , so the range of change of is $[-4.65,4.65]$. In order to use the parameters to evaluate the risk perception ability of female college students, this study divides the range of parameter $\alpha$ into three intervals. The first interval is below $60 \%$, the second interval is $60 \%-80 \%$, and the third interval is above $80 \%$. The distribution of these three intervals is $[-4.65,0.93],(0.93,2.79),(2.79,4.65]$. According to the calculation results of the first female college students' risk perception sensitivity parameter, the female college students' risk perception sensitivity is relatively low. Similarly, the risk sensitivity parameters of the other 19 female college students can be calculated. As shown in Table 3, all the values are at $[-4.65,0.93]$, so the risk perception sensitivity of 20 female college students is relatively low. 
Table 3. Perceived risk sensitivity results of 20 female college students

\begin{tabular}{|c|c|c|c|c|c|c|c|c|c|c|c|}
\hline & HR & FAR & $\Phi^{-1}(H R)$ & $\Phi^{-1}(F A R)$ & $\alpha$ & & HR & FAR & $\Phi^{-1}(H R)$ & $\Phi^{-1}(F A R)$ & $\alpha$ \\
\hline T1 & 0.8839 & 0.1731 & -1.19 & 0.94 & -2.13 & T11 & 0.8662 & 0.1833 & -1.11 & 0.90 & -2.01 \\
\hline $\mathrm{T} 2$ & 0.8417 & 0.1041 & -1.00 & 1.26 & -2.26 & $\mathrm{~T} 12$ & 0.7256 & 0.0113 & -0.06 & 2.22 & -2.82 \\
\hline $\mathrm{T} 3$ & 0.6675 & 0.0113 & -0.43 & 2.28 & -2.71 & $\mathrm{~T} 13$ & 0.7018 & 0.0521 & -0.54 & 1.62 & -2.16 \\
\hline $\mathrm{T} 4$ & 0.6939 & 0.0588 & -0.50 & 1.56 & -2.06 & $\mathrm{~T} 14$ & 0.7230 & 0.1154 & -0.61 & 1.20 & -1.81 \\
\hline $\mathrm{T} 5$ & 0.6108 & 0.0542 & -0.28 & 1.60 & -1.88 & $\mathrm{~T} 15$ & 0.8799 & 0.0814 & -1.17 & 1.40 & -2.57 \\
\hline $\mathrm{T} 6$ & 0.6939 & 0.0656 & -0.51 & 1.51 & -2.02 & $\mathrm{~T} 16$ & 0.7018 & 0.0475 & -0.53 & 1.67 & -2.20 \\
\hline $\mathrm{T} 7$ & 0.7441 & 0.0610 & -0.66 & 1.55 & -2.21 & $\mathrm{~T} 17$ & 0.7203 & 0.0361 & -0.58 & 1.79 & -2.37 \\
\hline $\mathrm{T} 8$ & 0.8734 & 0.2127 & -1.14 & 0.80 & -1.94 & $\mathrm{~T} 18$ & 0.7599 & 0.0792 & -0.71 & 1.41 & -2.12 \\
\hline $\mathrm{T} 9$ & 0.8021 & 0.0995 & -0.85 & 1.29 & -2.14 & $\mathrm{~T} 19$ & 0.7111 & 0.0271 & -0.55 & 1.92 & -2.47 \\
\hline $\mathrm{T} 10$ & 0.6451 & 0.0407 & -0.38 & 1.74 & -2.12 & $\mathrm{~T} 20$ & 0.7098 & 0.0792 & -0.55 & 1.41 & -1.96 \\
\hline
\end{tabular}

As shown in Table 4, the results of the reaction tendency of 20 female college students are statistically reflected. The value of the reaction tendency represents the response to the risk scenario. The larger the value, the more conservative the signal response of the testee, that is, the probability of the female college student taking risks is greater; The smaller the value, the more relaxed the standard for the respondent's signal response, that is, the risk judgment of the female college student is very cautious. From the results in Table 4, it can be seen that the minimum value of the 20 female college students tested was 0.7191 , and the largest was 12.2650. The difference was obvious, which reflected the difference in risk perception of female college students.

Table 4. Reaction tendency results of 20 female college students

\begin{tabular}{|c|c|c|c|c|c|c|c|}
\hline & $\mathrm{Y}(\mathrm{HR})$ & $\mathrm{Y}(\mathrm{FAR})$ & $\beta$ & & $\mathrm{Y}(\mathrm{HR})$ & $\mathrm{Y}(\mathrm{FAR})$ & $\beta$ \\
\hline T1 & 0.1965 & 0.2565 & 0.7662 & $\mathrm{~T} 11$ & 0.2155 & 0.2700 & 0.8097 \\
\hline T2 & 0.2400 & 0.1804 & 1.3415 & $\mathrm{~T} 12$ & 0.3300 & 0.0339 & 9.8178 \\
\hline T3 & 0.3637 & 0.0297 & 12.265 & $\mathrm{~T} 13$ & 0.3448 & 0.1074 & 3.2104 \\
\hline T4 & 0.3500 & 0.1181 & 2.9796 & $\mathrm{~T} 14$ & 0.3312 & 0.1900 & 1.7057 \\
\hline T5 & 0.3836 & 0.1100 & 3.4584 & $\mathrm{~T} 15$ & 0.2012 & 0.1500 & 1.3439 \\
\hline T6 & 0.3503 & 0.1276 & 2.7456 & $\mathrm{~T} 16$ & 0.3467 & 0.0989 & 3.5043 \\
\hline T7 & 0.3209 & 0.1200 & 2.6737 & $\mathrm{~T} 17$ & 0.3372 & 0.0804 & 4.1948 \\
\hline T8 & 0.2083 & 0.2900 & 0.7191 & $\mathrm{~T} 18$ & 0.3101 & 0.1476 & 2.1001 \\
\hline T9 & 0.2780 & 0.1736 & 1.6013 & $\mathrm{~T} 19$ & 0.3429 & 0.0632 & 5.4301 \\
\hline T10 & 0.3712 & 0.0878 & 4.2275 & $\mathrm{~T} 20$ & 0.3429 & 0.1476 & 2.3229 \\
\hline
\end{tabular}




\section{Conclusion}

Through the research results, it can be seen that the difference in risk perception sensitivity of female college students is small, but the risk perception response tendency among individuals is quite different. These findings can provide some theoretical advice for online mall apparel product operators. When selling apparel products to target customers like female college students, attention should be paid to reducing potential economic risks, performance risks, social risks and psychological risk factors. Because female college students' group perception sensitivity is generally low, and the risk perception response tendency is quite different. Therefore, when the online mall operators promote, display and sell products, they must ensure that the quality, delivery time and popularity of the products are consistent with the actual situation. In addition, the relevant departments must work together to ensure the environmental security of the online payment of the online mall. Higher education institutions also need to improve their network risk perception ability by setting up lectures or courses.

\section{Acknowledgements}

This paper is grateful for Guangdong Coastal Economic Belt Development Research Center.

\section{References}

[1] Bauer, R. A, “Consumer behavior as risk taking, In R.S. Hancock (Eds.), Dynamic marketing for a changing world”, American marketing Association, pp.389-398, (1960)

[2] Bisseret A., "Application of signal detection theory to decision making in supervisory control: the effect of the operator's experience," Ergonomics, vol.24, no.2, pp.81-94, (1981) DOI: 10.1080/00140138108924833

[3] ChangJo Yoo·HyeJu Jeong "An effects of perceived value and risk of mobile shopping on mobile shopping purchase intention: Moderating effect of the smartphone usage level," Korea Internet Electronic Commerce Association, vol.6, no.6, pp.59-76, (2016)

[4] Eun Joo Park and Bo Kyung Kim, "Effects of shopping orientation, marketing stimulus and perceived risk on e-impulse buying of shoes markets," Korean Journal of the science of Emotion \& sensibility, vol.19, no.1, pp.71-82, (2015) DOI: 10.14695/KJSOS.2016.19.1.71

[5] Kim Kyungmin, 'Lee Yeoungil, and·Zhang Zhonglai, "The influence on the difference of purchase intention of perceived risk of consumer and temporal distance between purchase and consumption," Korea Journal of Business Administration, vol.22, no.4, pp.1915-1935, (2009)

[6] Jun young Kim and Heon soo Jeong, "The influence of an internet shopping mall's characteristics on the purchase intentions," The Kon-Kuk Journal of Business and Economic Studies, vol.2, pp.129-185, (2016)

[7] Hu JingJing, "Analysis of current situation and limitation of internet shopping mall in China: Focused in payment method," M.S. thesis, Chung-Ang University, (2008)

[8] Jeun Sang-taek and Shim Tae Yong, "A study on the effect of shopping mall image continuity on economic risk and shopping attitude of internet customers in China: Focused on shopping value adjustment effect," Journal of Distribution and Management Research, vol.21, no.3, pp.147-159, (2018)

[9] Jiyong Lee and JinSook Hwang, "Purchase intention and risk perception in overseas direct purchase according to shopping orientation,” Korea Society of Design Trend, vol.1, no.46, pp.205-218, (2015) 


\section{Authors}

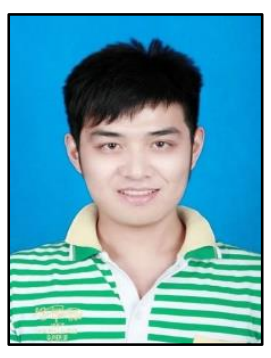

\section{Hewei Tian}

Doctorate programme in Dept. Fashion Design of Tongmyong University.

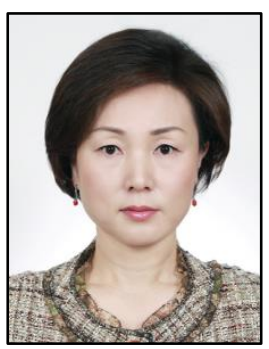

\section{Youngsook Lee}

Professor in Dept. Fashion Design of Tongmyong University. 
Research on Risk Perception of Fashion Online Shopping by Chinese Female College Students' in Guangdong

This page is empty by intention. 